\title{
Testes of obese rats are highly responsive to $n-3$ long-chain fatty acids
}

\author{
Miyoung Suh*, Krystal J. Merrells, Amy Dick and Carla G. Taylor \\ Department of Human Nutritional Sciences, University of Manitoba, Winnipeg, Manitoba, Canada R3T 2N2
}

(Received 27 August 2010 - Revised 10 January 2011 - Accepted 21 January 2011 - First published online 13 April 2011)

\section{Abstract}

The present study investigated whether fatty acid compositions of testes are affected by the obese condition and dietary $n$ - 3 long-chain fatty acid (LCFA) intake. Male lean and obese Zucker rats were fed a $15 \%$ (w/w, total diet) fat diet containing either 0 or $5 \cdot 0 \%$ (w/w, total fatty acids) $n$-3 LCFA for 8 weeks. Reproductive organ weights, sperm morphology and fatty acid composition of phosphatidylcholine (PC), and phosphatidylethanolamine (PE) of testes were analysed. The obese rats had significantly $(P<0 \cdot 0001)$ smaller epididymides and seminal vesicles, larger prostates and abundant underdeveloped testes compared with lean rats. Diet treatment did not affect the sex organ weights. The effect of genotype on fatty acid composition was minor in PC and PE except for DHA (22:6n-3). The $n-3$ LCFA diet significantly $(P<0 \cdot 0001)$ elevated $22: 6 n-3$ and reduced arachidonic acid $(20: 4 n-6)$ and DPA $(22: 5 n-6)$ in testicular PC and PE of lean and obese rats compared with the control diet. The acylation of dietary $n-3$ LCFA into 22:6n-3 was 2 -fold higher in obese rat testes than in lean rats fed the same diet. Underdeveloped testes had 70\% less 22:5n-6 in PC and PE than normal-size testes. Results indicate that testicular fatty acid composition is sensitive to dietary fat modulations and especially obese rats responded more to dietary $n-3$ LCFA than their lean counterparts. The selective reduction in 22:5n-6 in underdeveloped testes indicates that 22:5n-6 is important in male reproduction in rats and requires further study to define the role of elongation and desaturation in testicular development.

\section{Key words: DPA: Testes: $n$-3 Fatty acids: Sperm morphology: Obesity: Underdeveloped testes}

Although numerous studies have focused on obesityassociated reproductive abnormalities in females, little attention has been paid to male cases, including overall male reproductive health. Recently, more evidence has shown that male obesity is associated with poor semen quality including low sperm concentration and low progressively motile sperm count, lower rate of couple fertility, and low serum total and free testosterone levels ${ }^{(1-4)}$. The frequency of erectile dysfunction also increases with increasing $\mathrm{BMI}^{(5,6)}$. All of these problems are contributing factors to male infertility and raise concerns about an alarming trend in North America, since the obese population is increasing. According to Statistics $\mathrm{Canada}^{(7)}$, about $33 \%$ of adult Canadians are overweight and $15 \%$ are obese. In the USA, $64 \%$ of adults are overweight, over $30 \%$ are obese and $5 \%$ are extremely obese ${ }^{(8)}$.

Testes and sperm have a characteristic lipid composition that is highly enriched in long-chain PUFA (long-chain fatty acids; LCFA), predominantly DPA $(22: 5 n-6)$ in rats and DHA $(22: 6 n-3)$ in humans ${ }^{(9)}$. Although the specific functions of these fatty acids are not known, decreased $22: 6 n-3$ in the sperm phospholipid ${ }^{(10)}$ has been identified in infertile men and asthenozoospermic males ${ }^{(10,11)}$. Infertile men also exhibit a drastic loss of sperm phosphatidylethanolamine (PE) but significant increases of phosphatidylserine ${ }^{(12)}$. In rats, decreased levels of $22: 5 n-6$ are related to smaller testes ${ }^{(13,14)}$ and lower fertility ${ }^{(15)}$, which could be due to poor spermatid maturation ${ }^{(16)}$. These findings indicate that decreased sperm fertility potential is associated with alteration of sperm and testicular lipid composition of $n-6$ and $n$-3 LCFA. Whether levels of these fatty acids are altered in obese males are not known.

Dietary $n-6$ and $n-3$ fatty acid types have been shown to affect Sertoli cell lipids, the binding capacity of the luteinising hormone receptor in the testis, testosterone production in Leydig cells and reproductive capacity ${ }^{(17-19)}$. In addition, alteration of the content and the ratio of $n-6$ and $n-3$ fatty acids in the diet has been found to influence eicosanoid synthesis and metabolism, and affect the fertilising ability in males ${ }^{(20)}$. This implies that dietary lipids, such as $n-6$ and $n-3$ fatty acids, could be important factors influencing testicular function and reproductive performance. In fact, dietary $22: 6 n-3$, more efficiently than arachidonic acid $(20: 4 n-6)$, restored fertility, sperm count and spermiogenesis in $22: 5 n-6-$ and $22: 6 n-3-$ deficient $\Delta-6$ desaturase-null mice ${ }^{(21)}$. This study indicates the importance of $n-3$ LCFA, perhaps the balance of $n-3$ and $n-6$ LCFA, in fertility, even in the $n-6$ LCFA-enriched rodent testis.

The Zucker obese $(f a / f a)$ rat has a somatic mutation in the leptin receptor gene and is a widely used animal model for human obesity studies ${ }^{(22)}$. This animal model exhibits many

Abbreviations: LCFA, long-chain fatty acid; PC, phosphatidylcholine; PE, phosphatidylethanolamine.

*Corresponding author: Dr Miyoung Suh, fax +1 204474 7593, email suh@ms.umanitoba.ca 
pathological features similar to human obesity such as hyperphagia, hyperinsulinaemia, hyperlipidaemia, but not hyperglycaemia, as seen in the obese Zucker diabetic fatty male rat. By using this animal model, we investigated whether fatty acid compositions in the major phospholipids of testes are affected by the obese condition as well as dietary $n-3$ LCFA treatment.

\section{Materials and methods}

\section{Animals and diets}

Male lean $(n ; n$ 12) and obese $(f a / f a ; n$ 12) Zucker rats, aged 6 weeks (Harlan, Indianapolis, IN, USA), were randomly assigned to two experimental diet groups (six rats per group) and fed semi-purified diets containing 15\% (w/w) fat for 8 weeks. The basal diet contained (per kg): casein $(270 \mathrm{~g})$, maize starch (214 g), dextrose (217 g), cellulose ( $80 \mathrm{~g})$, vitamin mix $(9.5 \mathrm{~g})$, mineral mix $(48 \mathrm{~g})$, choline $(2.75 \mathrm{~g})$, inositol $(6.25 \mathrm{~g})$ and L-methionine $(2.5 \mathrm{~g})$ as previously described with a slight increase in maize starch ${ }^{(23)}$. Diets differed in $n-3$ LCFA level, $0 v .5 \%$ (w/w of total fatty acids) by using fish oil as the source of $n-3$ LCFA (Ocean Nutrition Canada, Mulgrave, NS, Canada) (Table 1). The mixture of fat and the fatty acid composition of the diets that were fed are presented in Table 1. Animals were housed in a controlled environment of $21-23^{\circ} \mathrm{C}, 55 \%$ humidity and $14 \mathrm{~h}$ light $-10 \mathrm{~h}$ dark cycles. Animals were allowed access to feed and water ad libitum.

Animals were euthanised by $\mathrm{CO}_{2}$ asphyxiation and decapitation after a $12 \mathrm{~h}$ overnight fast. Body weights, and epididymal, testicular, seminal vesicular and prostate weights were recorded. Excised testes and epididymides were immediately frozen in liquid $\mathrm{N}_{2}$, and stored at $-80^{\circ} \mathrm{C}$. Animal care procedures were based on guidelines described in the

Table 1. Fatty acid composition of the experimental diets

\begin{tabular}{|c|c|c|}
\hline & \multicolumn{2}{|c|}{ Diet } \\
\hline & Control & $n-3$ LCFA $^{*}$ \\
\hline \multicolumn{3}{|l|}{ Fat mix $(\mathrm{g} / \mathrm{kg})$} \\
\hline Flaxseed & $3 \cdot 0$ & $3 \cdot 0$ \\
\hline Olive & $4 \cdot 5$ & 4.5 \\
\hline Tallow & 89.55 & $89 \cdot 76$ \\
\hline Sunflower-seed & 52.95 & $37 \cdot 73$ \\
\hline Fish oil & 0.0 & $15 \cdot 0$ \\
\hline \multicolumn{3}{|c|}{ Fatty acids $\operatorname{mix}(\%, w / w)$} \\
\hline $14: 0$ & 0.09 & 1.97 \\
\hline $16: 0$ & $8 \cdot 90$ & $19 \cdot 37$ \\
\hline $18: 0$ & $52 \cdot 14$ & $41 \cdot 25$ \\
\hline $18: 1$ & $12 \cdot 42$ & $9 \cdot 74$ \\
\hline $18: 2 n-6$ & 21.41 & $16 \cdot 27$ \\
\hline $18: 3 n-3$ & $1 \cdot 25$ & $1 \cdot 30$ \\
\hline $20: 4 n-6$ & - & 0.19 \\
\hline $20: 5 n-3$ & - & 3.46 \\
\hline $22: 6 n-3$ & - & 1.58 \\
\hline$\Sigma$ SFA & $64 \cdot 40$ & 64.42 \\
\hline$\Sigma$ MUFA & $12 \cdot 50$ & $10 \cdot 96$ \\
\hline$\Sigma n-6$ Fatty acids & 21.41 & $16 \cdot 63$ \\
\hline$\sum n-3$ Fatty acids & 1.48 & $6 \cdot 79$ \\
\hline$\sum n-6: \Sigma n-3$ Ratio & $14 \cdot 5$ & 2.5 \\
\hline Total PUFA:SFA & 0.36 & 0.36 \\
\hline
\end{tabular}

LCFA, long-chain fatty acids.

${ }^{*}$ Containing both EPA $(20: 5 n-3)$ and DHA $(22: 6 n-3)$
Canadian Council for Animal Care. The study was approved by the University of Manitoba, Fort Garry Campus Protocol Management and Review Committee.

\section{Caudal epididymal sperm morphology}

Caudal epididymis was minced to release the spermatozoa in $2 \mathrm{ml}$ saline $(0.9 \% \mathrm{NaCl})$. A sample of minced caudal epididymis was fixed with $200 \mu \mathrm{l}$ formalin and stained with eosin Y. The sperm morphology for head and tail abnormality was assessed in 200 sperm using 400X conventional light microscopy (Olympus EH, Tokyo, Japan; Sony CCD model XC-711 camera, Tokyo, Japan). Sperm morphology was assessed according to Sprando et al. ${ }^{(24)}$ and the Rat Sperm Morphological Assessment Guideline Document $^{(25)}$.

\section{Lipid analysis}

Total lipids were extracted from decapsulated testes by the Folch method ${ }^{(26)}$. Phospholipids were separated on hexane pre-washed silica-gel H-plates $(20 \times 20 \mathrm{~cm})$ by developing in a prepared tank of chloroform-methanol-2-propanol-0.25\% (w/v) KCl-triethylamine (30:9:25:6:18, by vol.) ${ }^{(27)}$. Individual phospholipid bands were visualised with $0 \cdot 1 \%$ aniline naphthalene sulfonic acid in water (w/v) under UV light. Fatty acid methyl esters were prepared using $14 \% \mathrm{BF}_{3}$ in methanol ${ }^{(28)}$.

\section{Fatty acid analysis}

Separation of fatty acid methyl esters was performed on a SGE BPX 70 capillary column $(35 \mathrm{~m} \times 25 \mathrm{~mm}$ internal diameter with $0.25 \mu \mathrm{m}$ thickness) using a Shimadzu GC17A chromatograph (Mandel Scientific Co. Ltd, Guelph, ON, Canada). $\mathrm{H}_{2}$ was used as a carrier gas at a flow rate of $2.5 \mathrm{ml} / \mathrm{min}$. The temperature programme profile was as follows: $130^{\circ} \mathrm{C}$ held for $0 \mathrm{~min} ; 10^{\circ} \mathrm{C} / \mathrm{min}$ up to $150^{\circ} \mathrm{C}$, held for $0 \mathrm{~min}$; $1^{\circ} \mathrm{C} / \mathrm{min}$ up to $190^{\circ} \mathrm{C}$, held for $0 \mathrm{~min} ; 3^{\circ} \mathrm{C} / \mathrm{min}$ up to $240^{\circ} \mathrm{C}$, held for $15 \mathrm{~min}$. Injection temperature was $275^{\circ} \mathrm{C}$, and detector temperature was $320^{\circ} \mathrm{C}$. All fatty acids were compared with a commercial standard (NuChek Prep 461).

\section{Statistical analysis}

The effect of genotype and diet on sperm morphology and phospholipid fatty acid composition in testes and epididymides was analysed by two-way ANOVA using statistical software (SAS version 9.1; SAS Institute, Inc., Cary, NC, USA). Significant effects of treatment were defined using Duncan's multiple-range test ${ }^{(29)}$. All data are expressed as mean values and standard deviations.

\section{Results}

\section{Body and organ weights and sperm morphology}

Genotype differences were found in body and organ weights between the lean and obese animals. The obese rats in the control and n-3 LCFA groups had a significantly higher body weight, 42.5 and $27.4 \%$, respectively, than the lean animals 
Table 2. Effect of dietary $n-3$ long-chain fatty acids (LCFA) on organ weight of lean and obese Zucker rats

(Mean values and standard deviations for six rats per group)

\begin{tabular}{|c|c|c|c|c|c|c|c|c|c|c|c|}
\hline \multirow{3}{*}{ Diet ... } & \multicolumn{4}{|c|}{ Lean } & \multicolumn{4}{|c|}{ Obese } & & & \\
\hline & \multicolumn{2}{|c|}{ Control } & \multicolumn{2}{|c|}{$n-3$ LCFA } & \multicolumn{2}{|c|}{ Control } & \multicolumn{2}{|c|}{$n-3$ LCFA } & \multicolumn{3}{|c|}{ Significant effects $(P)^{*}$} \\
\hline & Mean & SD & Mean & SD & Mean & SD & Mean & SD & Genotype & Diet & $\begin{array}{c}\text { Genotype } \\
\times \text { diet }\end{array}$ \\
\hline Body weight (g) & $311 \cdot 3^{b}$ & $16 \cdot 5$ & $319 \cdot 9^{b}$ & $14 \cdot 1$ & $427 \cdot 4^{\mathrm{a}}$ & $44 \cdot 1$ & $407 \cdot 5^{\mathrm{a}}$ & 93.2 & $<0.0001$ & NS & NS \\
\hline Testes $(\mathrm{g}) \dagger$ & 2.94 & 0.75 & $2 \cdot 82$ & 0.22 & $2 \cdot 28$ & 0.38 & 3.00 & $1 \cdot 10$ & NS & NS & NS \\
\hline Epididymides $(\mathrm{g}) \dagger$ & $0.81^{\mathrm{b}}$ & 0.09 & $0.87^{a}$ & 0.06 & $0.52^{c}$ & 0.07 & $0.56^{c}$ & 0.13 & $<0.0001$ & NS & NS \\
\hline Prostate gland $(\mathrm{g})$ & $0.40^{\mathrm{b}}$ & 0.09 & $0.43^{\mathrm{b}}$ & 0.12 & $1 \cdot 18^{\mathrm{a}}$ & 0.26 & $1.00^{\mathrm{a}}$ & 0.50 & $<0.0001$ & NS & NS \\
\hline Seminal vesicles $(\mathrm{g})$ & $0.62^{\mathrm{a}}$ & 0.05 & $0.70^{\mathrm{a}}$ & 0.22 & $0.30^{\mathrm{b}}$ & 0.08 & $0.32^{\mathrm{b}}$ & 0.19 & $<0.0001$ & NS & NS \\
\hline \multicolumn{12}{|c|}{ Relative to body weight (\%, w/w) } \\
\hline Testes & $0.98^{a}$ & 0.25 & $0.88^{a, b}$ & 0.08 & $0.54^{\mathrm{C}}$ & 0.13 & $0.74^{b, c}$ & 0.23 & 0.0010 & NS & NS \\
\hline Epididymides & $0.38^{\mathrm{b}}$ & 0.04 & $0.44^{\mathrm{a}}$ & 0.03 & $0.26^{c}$ & 0.03 & $0.28^{\mathrm{c}}$ & 0.07 & $<0.0001$ & NS & NS \\
\hline Prostate gland & $0.13^{\mathrm{b}}$ & 0.03 & $0.14^{\mathrm{b}}$ & 0.04 & $0.27^{a}$ & 0.04 & $0.23^{\mathrm{a}}$ & 0.08 & $<0.0001$ & NS & NS \\
\hline Seminal vesicles & $0.21^{a}$ & 0.02 & $0.22^{a}$ & 0.03 & $0.07^{\mathrm{b}}$ & 0.02 & $0.08^{\mathrm{b}}$ & 0.04 & $<0.0001$ & NS & NS \\
\hline
\end{tabular}

a,b,c Mean values within a row with unlike superscript letters were significantly different by multiple comparison $(P<0.05)$.

* Significant effects of genotype and diet were identified by two-way ANOVA.

†Paired weights.

fed the same diet, as was expected (Table 2). In both absolute ( $\mathrm{g}$ ) and relative (\% of body weight) weight, the obese rats had significantly smaller paired epididymides and seminal vesicles, but larger prostate glands in comparison with their lean counterparts $(P<0 \cdot 0001)$ (Table 2$)$. There were no differences in the absolute weight of paired testes, but a significantly lower relative testicular weight $(P<0.001)$ was observed in obese rats. These body and organ weights were independent of dietary treatment. Testes and reproductive accessory organs are shown in Fig. 1. Interestingly, the obese rats had noticeably shorter epididymides. It was found that $35 \%$ of lean rats and $60 \%$ of obese rats showed differences in each testes pair, with a range of $1 \cdot 2$ - to $2 \cdot 7$-fold more in the larger testes than the underdeveloped testes (data not shown).

Overall sperm integrity was not affected by genotype or diet. More than $50 \%$ of sperm from obese rats were morphologically abnormal in both diet groups but no differences were found for the lean rats. This might be due to a large variation in sperm integrity, for example, the normal sperm in obese rats fed the $n$-3 LCFA diet ranged from 0 to 153 among 200 sperm counted. The obese rats on the $n$ - 3 LCFA diet had fewer tail abnormalities but more head abnormalities (16.4 (SD 12.5) and 23.0 (SD 22.5) \%, respectively) than the obese rats fed the control diet (33.9 (SD 17.7) and 4.2 (SD 2.6) \%, respectively). Head abnormalities were identified as headless sperm, sperm with bent necks, or pinheads. Tail abnormalities included bent or coiled tails.

\section{Fatty acid composition in testicular phospholipids}

Fatty acid composition was determined in phosphatidylcholine (PC) and PE, since these are the most abundant phospholipids found in the testis. (a)

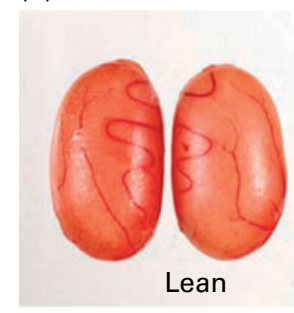

(c) (b)

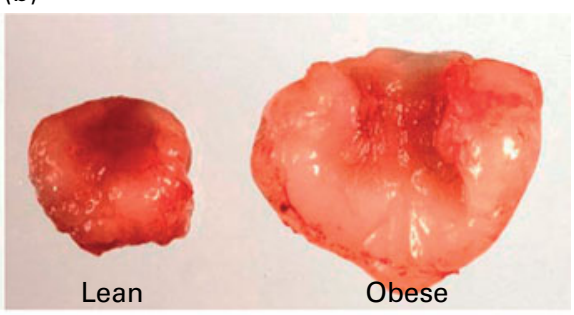

(d)

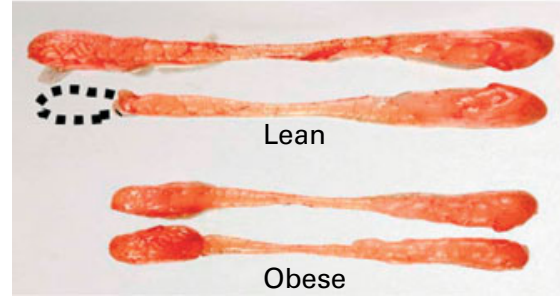

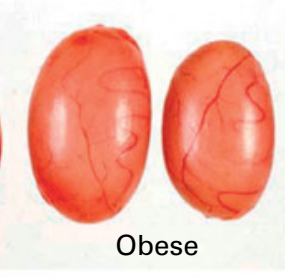


Table 3. Effect of dietary $n-3$ long-chain fatty acids (LCFA) on fatty acid composition of phosphatidylcholine in the testes of lean and obese Zucker rats (Mean values and standard deviations)

\begin{tabular}{|c|c|c|c|c|c|c|c|c|c|c|c|}
\hline \multirow{3}{*}{$\begin{array}{l}\text { Diet... } \\
\text { Fatty acids }(\%, w / w)\end{array}$} & \multicolumn{4}{|c|}{ Lean } & \multicolumn{4}{|c|}{ Obese } & & & \\
\hline & \multicolumn{2}{|c|}{ Control (n 4) } & \multicolumn{2}{|c|}{$n-3$ LCFA $(n 6)$} & \multicolumn{2}{|c|}{ Control $(n 3)$} & \multicolumn{2}{|c|}{$n-3$ LCFA $(n 5)$} & \multicolumn{3}{|c|}{ Significant effects $(P)^{*}$} \\
\hline & Mean & SD & Mean & SD & Mean & SD & Mean & SD & Genotype & Diet & $\begin{array}{c}\text { Genotyp } \\
\times \text { diet }\end{array}$ \\
\hline $14: 0$ & $0 \cdot 19$ & 0.06 & 0.21 & 0.11 & $0 \cdot 10$ & 0.06 & 0.19 & 0.02 & NS & 0.0085 & NS \\
\hline $16: 0$ & 37.48 & 2.95 & 37.54 & 1.87 & $40 \cdot 18$ & 1.77 & 37.63 & 2.09 & & & \\
\hline $16: 1(n-5+n-7)$ & $0.76^{\mathrm{b}}$ & 0.08 & $1 \cdot 11^{a, b}$ & 0.30 & $0.67^{\mathrm{b}}$ & 0.12 & $1 \cdot 22^{\mathrm{a}}$ & 0.42 & NS & 0.0085 & NS \\
\hline $18: 0$ & $6 \cdot 20$ & 1.01 & $5 \cdot 39$ & 1.20 & 5.57 & 0.86 & 4.57 & 0.94 & & & \\
\hline $18: 1(n-7+n-9)$ & 14.93 & $1 \cdot 11$ & $15 \cdot 36$ & 0.97 & $16 \cdot 76$ & $2 \cdot 15$ & $16 \cdot 71$ & 1.46 & & & \\
\hline $18: 2 n-6$ & $4 \cdot 15^{\mathrm{b}}$ & 0.79 & $4 \cdot 60^{\mathrm{a}, \mathrm{b}}$ & 0.70 & $4 \cdot 08^{\mathrm{b}}$ & 0.41 & $6 \cdot 25^{\mathrm{a}}$ & 1.82 & NS & 0.0320 & NS \\
\hline $18: 3 n-3$ & nd & & nd & & nd & & nd & & & & \\
\hline $20: 2 n-6$ & $0 \cdot 12^{a, b}$ & $0 \cdot 10$ & $0.06^{b}$ & 0.05 & $0.04^{b}$ & 0.07 & $0.19^{a}$ & 0.03 & NS & NS & 0.0045 \\
\hline $20: 3 n-6$ & $1.50^{\mathrm{C}}$ & 0.27 & $2 \cdot 03^{\mathrm{b}, \mathrm{c}}$ & 0.26 & $1.76^{\mathrm{b}}$ & 0.21 & $2 \cdot 42^{\mathrm{a}}$ & 0.07 & 0.0077 & $<0.0001$ & NS \\
\hline $20: 4 n-6$ & $14.55^{a}$ & 1.04 & $13 \cdot 13^{\mathrm{b}}$ & 0.46 & $13 \cdot 88^{a, b}$ & 0.41 & $11.45^{\mathrm{c}}$ & 0.98 & 0.0080 & 0.0002 & NS \\
\hline $22: 4 n-6$ & $1 \cdot 15^{\mathrm{a}}$ & 0.09 & $0 \cdot 71^{\mathrm{a}, \mathrm{b}}$ & 0.35 & $0.86^{\mathrm{b}}$ & 0.18 & $0.81^{a, b}$ & 0.06 & NS & 0.0385 & NS \\
\hline $22: 5 n-6$ & $13 \cdot 70$ & 2.73 & 14.96 & $1 \cdot 12$ & 13.60 & 2.50 & $12 \cdot 31$ & 1.61 & & & \\
\hline $22: 5 n-3$ & 0.08 & 0.14 & 0.15 & 0.25 & 0.00 & 0.00 & 0.12 & 0.03 & & & \\
\hline $22: 6 n-3$ & $0.53^{\mathrm{C}}$ & 0.10 & $1.28^{\mathrm{b}}$ & 0.35 & $0.52^{\mathrm{C}}$ & 0.26 & $3.00^{\mathrm{a}}$ & 0.72 & 0.0017 & $<0.0001$ & 0.0014 \\
\hline $24: 4 n-6$ & 0.80 & $0 \cdot 12$ & 0.69 & 0.11 & 0.75 & 0.12 & 0.72 & 0.07 & & & \\
\hline $24: 5 n-6$ & 0.71 & 0.17 & 0.72 & 0.17 & 0.57 & 0.21 & 0.73 & 0.03 & & & \\
\hline $24: 5 n-3$ & $0.01^{b}$ & 0.01 & $0.00^{\mathrm{b}}$ & 0.00 & $0.00^{b}$ & 0.00 & $0.04^{a}$ & 0.01 & 0.0006 & 0.0129 & 0.0006 \\
\hline $24: 6 n-3$ & $0.03^{b}$ & 0.03 & $0.01^{b}$ & 0.02 & $0.00^{\mathrm{b}}$ & 0.01 & $0 \cdot 16^{\mathrm{a}}$ & 0.05 & 0.0003 & 0.0032 & 0.0004 \\
\hline$\Sigma$ SFA & $46 \cdot 68^{\mathrm{a}, \mathrm{b}}$ & 1.65 & $44 \cdot 00^{\mathrm{a}, \mathrm{b}}$ & $2 \cdot 30$ & $46 \cdot 00^{\mathrm{a}}$ & 2.44 & $42.59^{b}$ & 1.94 & NS & 0.0363 & NS \\
\hline$\Sigma$ MUFA & $15 \cdot 75^{\mathrm{a}}$ & 1.09 & $16 \cdot 51^{a, b}$ & 0.86 & $17 \cdot 46^{a, b}$ & 1.98 & $18 \cdot 20^{b}$ & $2 \cdot 22$ & 0.0264 & NS & NS \\
\hline$\sum n-6$ Fatty acids & 33.02 & 4.91 & 32.52 & 2.68 & 31.68 & 3.88 & $29 \cdot 11$ & 2.95 & & & \\
\hline$\sum n$-3 Fatty acids & $0.70^{\mathrm{C}}$ & 0.31 & $1.48^{\mathrm{b}}$ & 0.64 & $0.56^{\mathrm{c}}$ & 0.33 & $3 \cdot 24^{\mathrm{a}}$ & 0.77 & 0.0010 & $<0.0001$ & 0.0140 \\
\hline$n-6: n-3$ Ratio & $63 \cdot 50^{\mathrm{a}}$ & $21 \cdot 18$ & $26 \cdot 29^{b}$ & 4.56 & $76 \cdot 69^{a}$ & $24 \cdot 23$ & $11.02^{\mathrm{b}}$ & $2 \cdot 26$ & NS & 0.0034 & NS \\
\hline
\end{tabular}

nd, Not detected.

a,b,c Mean values within a row with unlike superscript letters were significantly different by multiple comparison $(P<0 \cdot 05)$.

* Significant effects of genotype and diet were identified by two-way ANOVA.

\section{Phosphatidylcholine}

Both genotype and diet significantly altered the fatty acid composition in PC (Table 3). Obese rats had higher levels of dihomo- $\gamma$-linolenic acid $(20: 3 n-6)$ and total MUFA, but lower $20: 4 n-6$ compared with lean rats. The n-3 LCFA diet significantly elevated myristic acid (14:0), $16: 1$, linoleic acid (18:2n-6), 20:3n-6 while decreasing 20:4n-6, adrenic acid (22:4n-6) and total SFA in comparison with the control diet. The level of 22:6n-3 was also higher in both lean and obese animals after being fed the $n$ - 3 LCFA diet. The acylation of dietary $n$-3 LCFA into $22: 6 n-3$ was 2.4 times higher in obese rats than in the lean animals fed the same diet. Tetracosapentaenoic acid (24:5n-3) and tetracosahexaenoic acid (nisinic acid; 24:6n-3) were also higher in obese rats fed the $n-3$ LCFA diet. Overall, the $n$-3 LCFA diet significantly decreased the total $n-6: n-3$ fatty acids ratio in testicular PC. The predominant LCFA in testicular PC were $20: 4 n-6(11.5-14.6 \%, \mathrm{w} / \mathrm{w})$ and $22: 5 n-6(12 \cdot 3-14 \cdot 6 \%, \mathrm{w} / \mathrm{w})$ (Table 3$)$.

\section{Phosphatidylethanolamine}

The genotype effect on fatty acid composition in PE was minor. Obese animals had higher 22:6n-3 and 24:6n-3 and lower 22:5n-6 than their lean counterparts. The genotype differences became evident when animals were fed the $n$-3 LCFA diet by further elevating 22:6n-3 and 24:6n-3 while decreasing $22: 5 n-6$ in obese rats in comparison with lean rats fed the same diet. Rats fed the $n-3$ LCFA diet had higher levels of $18: 2 n-6,20: 3 n-6,22: 5 n-3$ and tetracosapentaenoic acid (24:5n-6) but lower $20: 4 n-6$ and $22: 4 n-6$ in comparison with those fed the control diet. Similar to PC, the acylation of dietary n-3 LCFA into $22: 6 n$-3 was 1.6 times higher in obese rats than in the lean rats fed the same diet. This resulted in a significant low total $n-6: n-3$ fatty acids ratio in PE. The major LCFA in PE were also $20: 4 n-6(20 \cdot 3-22 \cdot 5 \%$, w/w) and $22: 5 n-6(20 \cdot 6-26 \cdot 2 \%, \mathrm{w} / \mathrm{w})$ (Table 4$)$.

\section{Fatty acid composition in underdeveloped testes}

The fatty acid composition of underdeveloped testes was compared with that of normal-size testes. Among those analysed for fatty acids, only one or two rats per diet group showed over $30 \%$ differences in size between the paired testes; the underdeveloped testes were grouped together regardless of diet and genotype. Thus the following data present underdeveloped ( $n$ 4) and normal ( $n$ 18)-size testes using a typical gas chromatogram (see Fig. 2). The underdeveloped testes had characteristically low $(P<0 \cdot 0001) 22: 5 n-6$ in both PC $(72 \%$ less; 3.9 (SD 3.3) \%) and PE (71\% less; 6.8\% (SD 2.4) \%) when compared with normal-sized testes (13.7 (SD 2.0) and 24.2 (SD 2.6) $\%$ in $\mathrm{PC}$ and $\mathrm{PE}$, respectively). However, $20: 4 n-6$, the precursor of $22: 5 n-6$, was significantly $(P<0.0005)$ increased in PC $(13 \cdot 1$ (SD 1.4) and 18.3 (SD 5.0) $\%$ in normal and underdeveloped testes, respectively). Compared with the level of $22: 5 n-6$ in PC of normal-size testes in Table 3, the level in the underdeveloped testes of the 
Table 4. Effect of dietary $n-3$ long-chain fatty acids (LCFA) on fatty acid composition of phosphatidylethanolamine in the testes of lean and obese Zucker rats

(Mean values and standard deviations)

\begin{tabular}{|c|c|c|c|c|c|c|c|c|c|c|c|}
\hline \multirow{3}{*}{$\begin{array}{l}\text { Diet... } \\
\text { Fatty acid }(\%, w / w)\end{array}$} & \multicolumn{4}{|c|}{ Lean } & \multicolumn{4}{|c|}{ Obese } & & & \\
\hline & \multicolumn{2}{|c|}{ Control (n 4) } & \multicolumn{2}{|c|}{$n-3$ LCFA $(n 6)$} & \multicolumn{2}{|c|}{ Control (n 4) } & \multicolumn{2}{|c|}{$n-3$ LCFA $(n 5)$} & \multicolumn{3}{|c|}{ Significant effect $(P)^{\star}$} \\
\hline & Mean & SD & Mean & SD & Mean & SD & Mean & SD & Genotype & Diet & $\begin{array}{c}\text { Genotype } \\
\times \text { diet }\end{array}$ \\
\hline $14: 0$ & 0.07 & 0.08 & 0.05 & 0.04 & 0.01 & 0.01 & 0.04 & 0.01 & & & \\
\hline $16: 0$ & $20 \cdot 18$ & 1.52 & 20.09 & 1.43 & 23.50 & $5 \cdot 19$ & $20 \cdot 81$ & 1.37 & & & \\
\hline $16: 1(n-5+n-7)$ & $0.61^{\mathrm{a}}$ & 0.28 & $0.46^{\mathrm{a}}$ & 0.20 & $0.12^{\mathrm{b}}$ & 0.14 & $0.54^{\mathrm{a}}$ & 0.19 & NS & NS & 0.0100 \\
\hline $18: 0$ & $9 \cdot 26$ & 1.49 & $9 \cdot 28$ & 0.33 & 9.43 & 0.35 & 9.57 & 0.70 & & & \\
\hline $18: 1(n-7+n-9)$ & $7 \cdot 38$ & 1.33 & $7 \cdot 16$ & 0.26 & $6 \cdot 88$ & 1.54 & $8 \cdot 32$ & 0.76 & & & \\
\hline $18: 2 n-6$ & $1 \cdot 77^{\mathrm{b}}$ & 0.21 & $2 \cdot 37^{\mathrm{a}, \mathrm{b}}$ & 0.48 & $1 \cdot 56^{b}$ & 1.06 & $2 \cdot 70^{\mathrm{a}}$ & 0.58 & NS & 0.0096 & NS \\
\hline $20: 1$ & 0.04 & 0.04 & 0.06 & 0.03 & 0.04 & 0.05 & 0.09 & 0.01 & & & \\
\hline $20: 2 n-6$ & 0.03 & 0.03 & 0.06 & 0.04 & 0.03 & 0.03 & 0.07 & 0.02 & & & \\
\hline $20: 3 n-6$ & $0.49^{b}$ & 0.03 & $0.67^{a, b}$ & 0.07 & $0.51^{b}$ & 0.34 & $0.88^{a}$ & 0.15 & NS & 0.0042 & NS \\
\hline $20: 4 n-6$ & $21.59^{a, b}$ & $2 \cdot 35$ & $20 \cdot 29^{\mathrm{b}}$ & 0.77 & $22 \cdot 52^{\mathrm{a}}$ & 0.93 & $20 \cdot 32^{\mathrm{b}}$ & 1.03 & NS & 0.0123 & NS \\
\hline $22: 4 n-6$ & $3 \cdot 24^{\mathrm{a}}$ & 0.61 & $2.51^{\mathrm{b}}$ & 0.25 & $2 \cdot 86^{a, b}$ & 0.50 & $2 \cdot 39^{b}$ & 0.25 & NS & 0.0055 & NS \\
\hline $22: 5 n-6$ & $24 \cdot 81^{a}$ & $2 \cdot 71$ & $25 \cdot 29^{a}$ & 0.80 & $26 \cdot 23^{a}$ & 1.44 & $20 \cdot 61^{b}$ & 0.86 & 0.0356 & 0.0024 & 0.0006 \\
\hline $22: 5 n-3$ & $0.09^{b}$ & 0.19 & $0.21^{a, b}$ & 0.12 & $0.02^{\mathrm{b}}$ & 0.04 & $0.34^{a}$ & 0.15 & NS & 0.0034 & NS \\
\hline $22: 6 n-3$ & $0.98^{c}$ & 0.21 & $2 \cdot 74^{\mathrm{b}}$ & 0.34 & $1 \cdot 31^{\mathrm{C}}$ & 0.24 & $5 \cdot 76^{\mathrm{a}}$ & 1.58 & 0.0007 & $<0.0001$ & 0.0039 \\
\hline $24: 4 n-6$ & 0.84 & 0.12 & 0.81 & 0.07 & 0.68 & 0.47 & 0.76 & 0.09 & & & \\
\hline $24: 5 n-6$ & $0 \cdot 88^{a, b}$ & 0.14 & $1 \cdot 01^{a}$ & 0.14 & $0.60^{b}$ & 0.43 & $0.92^{a, b}$ & 0.09 & NS & 0.0484 & NS \\
\hline $24: 5 n-3$ & nd & & nd & & nd & & nd & & & & \\
\hline $24: 6 n-3$ & $0.03^{b}$ & 0.06 & $0.04^{\mathrm{b}}$ & 0.03 & $0.00^{\mathrm{b}}$ & 0.00 & $0.11^{a}$ & 0.04 & $<0.0001$ & $<0.0001$ & $<0.0001$ \\
\hline$\Sigma$ SFA & $30 \cdot 38$ & 4.35 & 29.82 & $2 \cdot 16$ & 33.00 & $5 \cdot 67$ & 30.74 & $2 \cdot 13$ & & & \\
\hline$\Sigma$ MUFA & $8 \cdot 02^{a, b}$ & 1.69 & $7 \cdot 69^{a, b}$ & 0.59 & $7.04^{\mathrm{b}}$ & 1.80 & $8.95^{a}$ & 1.67 & NS & NS & 0.0403 \\
\hline$\sum n-6$ Fatty acids & $52 \cdot 82^{\mathrm{a}}$ & $6 \cdot 15$ & $52 \cdot 10^{\mathrm{a}}$ & 2.54 & $54.39^{a}$ & $4 \cdot 81$ & $47 \cdot 88^{b}$ & 3.03 & NS & 0.0005 & 0.0047 \\
\hline$\Sigma n-3$ Fatty acids & $1.08^{\mathrm{c}}$ & 0.40 & $2 \cdot 95^{\mathrm{b}}$ & 0.46 & $1.33^{\mathrm{c}}$ & 0.28 & $6 \cdot 10^{\mathrm{a}}$ & $1 \cdot 73$ & 0.0008 & $<0.0001$ & 0.0029 \\
\hline$n-6: n-3$ Ratio & $53.92^{\mathrm{a}}$ & $17 \cdot 21$ & $17.95^{\mathrm{c}}$ & 2.43 & $41.85^{\mathrm{b}}$ & $7 \cdot 24$ & $8 \cdot 33^{c}$ & 2.35 & 0.0157 & $<0.0001$ & NS \\
\hline
\end{tabular}

nd, Not detected.

${ }^{\mathrm{a}, \mathrm{b}, \mathrm{c}}$ Mean values within a row with unlike superscript letters were significantly different by multiple comparison $(P<0 \cdot 05)$.

* Significant effects of genotype and diet were identified by two-way ANOVA.

lean control ( $n$ 1), obese control ( $n$ 2) and obese $n$-3 LCFA ( $n$ 1) groups was only $8 \cdot 8,2 \cdot 3$ and $2 \cdot 3 \%$, respectively. The level of $22: 5 n-6$ in underdeveloped testes PE in the lean control ( $n$ 1 ), obese control $(n 2)$ and obese $n$-3 LCFA ( $n$ 1) groups was also $9 \cdot 0,7 \cdot 8$ and $8 \cdot 0 \%$, respectively, much lower than the level in normal-size testes (Table 4). The underdeveloped testes also had higher stearic acid (18:0) in both phospholipid fractions (data not shown). The level of $22: 6 n-3$ was also low in $\mathrm{PC}$ and PE, but a significant difference was not found.

\section{Discussion}

Effect of genotype and dietary n-3 long-chain fatty acids on organ weights and sperm morphology

The present study found that the sizes of male sexual and accessory organs were affected by obesity. Obese Zucker rats had significantly smaller and shorter epididymides and seminal vesicles, but larger prostate glands. Obese rats had abundant unbalanced paired testis weights, leaving one testis underdeveloped. Both head and tail abnormalities in caudal epididymal sperm were also observed in obese rats. While there was no significant difference in overall sperm morphology between obese and lean animals, the $n$ - 3 LCFA diet decreased tail abnormalities but increased head abnormalities in obese rats. We noted a large variation in sperm morphology between rats in each diet group in this animal model; a larger sample size would confirm the effects of diet on sperm integrity. Although not measured in the present study, investigating sperm motility could perhaps explain its relationship with the epididymal length, since the spermatozoas undergo the maturation process to acquire motility function while moving progressively from caput, corpus, then to the caudal epididymis region. n-3 LCFA supplementation at the level of $5 \%(\mathrm{w} / \mathrm{w}$, total fatty acids) did not affect male sexual and accessory organ weights.

\section{Effect of genotype and dietary n-3 long-chain fatty acids on fatty acid compositions in phospholipids in testes}

The present study identified that there were no major differences in the fatty acid composition in phospholipids between lean and obese rats fed the control diet. Regardless of the genotype, the most quantitatively abundant LCFA found in the testes were 20:4n-6 and 22:5n-6 in PC (27-28\%) and PE (46-48\%), showing an $n$-6-enriched environment in the testes of rats. This finding has been confirmed by others ${ }^{(14)}$ and indicates that these fatty acids are minimally affected by the obese condition.

In response to dietary $n-3$ LCFA, both lean and obese rats increased the levels of $n-3$ fatty acids, especially $22: 6 n-3$, in testes at the expense of major $n-6$ fatty acids. This suggests that a competition for metabolic enzymes between $n-6$ and 


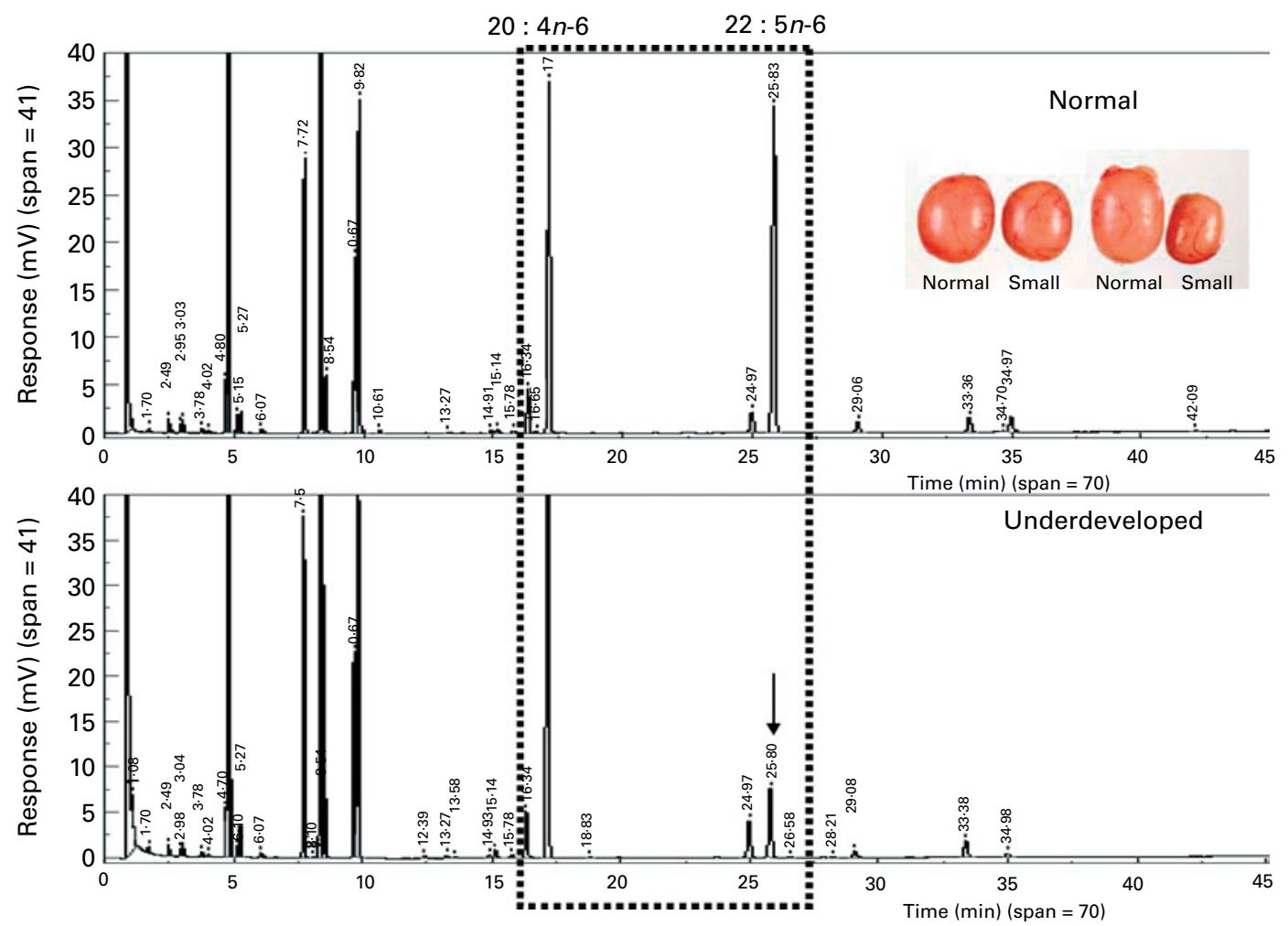

Fig. 2. A typical chromatogram showing the content of arachidonic acid $(20: 4 n-6)$ and DPA $(22: 5 n-6)$ in phosphatidylcholine in normal and underdeveloped testes.

$n$-3 fatty acids, with preformed $n$-3 fatty acids being the preferred substrate for metabolism and incorporation into tissue membranes, also occurred in the testis as found in other tissues ${ }^{(17,18,30,31)}$. Our findings demonstrate that the acylation of dietary $n-3$ fatty acids into testicular $22: 6 n-3$ was about 2-fold higher in obese Zucker rats in comparison with lean rats, suggesting that dietary $n-3$ manipulation has the greater effect in the obese condition. Guerre-Millo et $a l .{ }^{(32)}$ reported that plasma and intracellular membranes of adipocytes in obese Zucker rats decreased 2-fold in the $n-6: n-3$ fatty acids ratio mainly due to an enrichment in 22:6n-3 after treatment with a $22: 6 n$-3-containing diet. It may be that direct acylation of $22: 6 n-3$ into phospholipids is more active in obese Zucker rats, which requires further experimentation. It can also be postulated that our finding may be related to altered haemodynamics in testes in the obese condition, since blood flow through epididymides and testes was elevated in obese Zucker rats when expressed on a per $g$ tissue basis ${ }^{(33)}$. This is an interesting finding considering that obese males have more risk factors contributing to male infertility ${ }^{(1-4,34)}$. Overall, the study findings indicate that obese males with infertility problems may respond effectively to dietary lipid treatments and future studies need to address this in human subjects. Dietary intervention may have potential as an effective treatment for male reproductive problems by altering the major fatty acids for reducing infertility in oligo- and/or asthenozoospermic men ${ }^{(35)}$.

\section{DPA and underdeveloped testes and epididymides}

Although it is preliminary because of limited numbers measured, the present study found that the underdeveloped testis had dramatic decreases of $22: 5 n-6$ in major phospholipids. A current ongoing study in our laboratory with older Zucker obese rats also shows this phenomenon in the testis (M Suh, unpublished results). While not knowing if this decrease is the result or cause of testis underdevelopment, a similar selective decrease of 22:5n-6 was also identified in smaller rat testes, which were treated with doxorubicin, an antineoplastic drug, or had undergone surgery for cryptorchidism $^{(13,14)}$. The fatty acid $22: 5 n-6$ is known to be germ cellspecific and associated with spermatid maturation ${ }^{(16,36)}$. Thus a decrease in this fatty acid is related to germ cell deficiency. Due to limited sample numbers, the underdeveloped testes were all grouped together regardless of diet and obese condition; thus, further confirmation is required of whether $n-3$ LCFA are metabolised similarly in normal-size testes and improve or worsen the testicular function. Since the precursor fatty acid, 20:4n-6, was increased, the enzymes involved in $22: 4 n-6$ conversion to $22: 5 n-6$ could be blocked in the testes of this animal model. According to Sprecher's pathway $^{(37)}, \Delta-6$ desaturase enzyme may be responsible for this, thus further study is needed. Obese Zucker rats have low serum testosterone levels at age 2, 3 and 4 months compared with their lean counterparts ${ }^{(38)}$. Whether $22: 5 n-6$ is also involved in testicular testosterone production requires further investigation. 
There is limited research in relation to the effects of obesity and dietary responses on male reproductive health. The present study provides experimental evidence that the lipid microenvironment of phospholipids in the testes of obese rats can be efficiently modulated by dietary fat intervention. The clear benefits of $n$-3 LCFA in rats $v$. human subjects require further study. Considering Coniglio et al. ${ }^{(39)}$, postulation that $22: 6 n-3$ serves a function in the human testis similar to that served by $22: 5 n-6$ in the rat testis, dietary manipulation of $n-6$ or $n-3$ fatty acids and the resulting outcome found in rats can be translated to humans. The obese Zucker rat provides interesting characteristics in sex and accessory organs, especially unbalanced paired testis development. Whether germ cell populations are increased in proportion to the level of $22: 5 n-6$ needs further investigation. Hormonal changes not investigated in the present study merit exploration in future studies as well. The Zucker $(f a / f a)$ rat could be a useful model for further study on mechanisms involved in testis development and male fertility in the obese state. Overall, dietary fat can be an important determinant in male reproductive health.

\section{Acknowledgements}

The present study was supported by the Natural Sciences and Engineering Research Council of Canada and Manitoba Medical Service Foundation, and Agri-food Research Development Initiative. The authors appreciate the technical assistance of Mr Dennis Labossiere and thank Dr Catherine Field at the University of Alberta for the formula for the fat mixture and Dr Peter Zahradka for allowing us to take tissues from their study.

M. S. was responsible for overall data acquisition, analysis, interpretation and manuscript preparation. K. J. M. measured sperm morphology and contributed to the statistical analysis. A. D. contributed to fatty acid analysis. C. G. T. designed the nutritional intervention and contributed to animal care.

There are no conflicts of interest in the present study.

\section{References}

1. Magnusdottir EV, Thorsteinsson $\mathrm{T}$, Thorsteinsdottir $\mathrm{S}$, et al. (2005) Persistent organochlorines, sedentary occupation, obesity and human male subfertility. Hum Reprod 20, 208-215.

2. Hammoud AO, Wilde N, Gibson M, et al. (2008) Male obesity and alteration in sperm parameters. Fertil Steril 90, 2222-2225.

3. Sallmén M, Sandler DP, Hoppin JA, et al. (2006) Reduced fertility among overweight and obese men. Epidemiology $\mathbf{1 7}, 520-523$.

4. Mokdad AH, Bowman BA, Ford ES, et al. (2001) The continuing epidemics of obesity and diabetes in the United States. JAMA 286, 1195-1200.

5. Feldman HA, Goldstein I, Hatzichristou DG, et al. (1994) Impotence and its medical and psychosocial correlates: results of the Massachusetts Male Aging Study. J Urol 151, 54-61.

6. Bacon CG, Mittleman MA, Kawachi I, et al. (2003) Sexual function in men older than 50 years of age: results from the health professionals follow-up study. Ann Intern Med 139, 161-168.
7. Statistics Canada (2002) Canadian Community Health Survey: a first look. Ottawa, Canada: Statistics Canada (catalog no. 11-001E). http://www.statcan.gc.ca/daily-quotidien/020508/ dq020508a-eng.htm (accessed July 2010).

8. Flegal KM, Carroll MD, Ogden CL, et al. (2002) Prevalence and trends in obesity among US adults, 1999-2000. JAMA 288, 1723-1727.

9. Retterstøl K, Haugen TB, Tran TN, et al. (2001) Studies on the metabolism of essential fatty acids in isolated human testicular cells. Reproduction 121, 881-887.

10. Zalata AA, Christophe AB, Depuydt CE, et al. (1998) The fatty acid composition of phospholipids of spermatozoa from infertile patients. Mol Hum Reprod 4, 111-118.

11. Tavilani H, Doosti M, Nourmohammadi I, et al. (2007) Lipid composition of spermatozoa in normozoospermic and asthenozoospermic males. Prostaglandins Leukot Essent Fatty Acids 77, 45-50.

12. Gulaya NM, Margitich VM, Govseeva NM, et al. (2001) Phospholipid composition of human sperm and seminal plasma in relation to sperm fertility. Arch Androl 46, $169-175$.

13. Zanetti SR, Maldonado EN \& Aveldaño MI (2007) Doxorubicin affects testicular lipids with long-chain (C18-C22) and very long-chain (C24-C32) polyunsaturated fatty acids. Cancer Res 67, 6973-6980.

14. Furland NE, Maldonado EN, Aresti PA, et al. (2007) Changes in lipids containing long- and very long-chain polyunsaturated fatty acids in cryptorchid rat testes. Biol Reprod 77, 181-188.

15. Johnson AD (1970) Testicular lipids. In The Testis, pp. 193-258 [AD Johnson, WR Gomes and NL Vandermark, editors]. New York: Academic Press.

16. Davis JT, Bridges RB \& Coniglio JG (1966) Changes in lipid composition of the maturing rat testis. Biochem $J \mathbf{9 8}$, 342-346.

17. Blesbois E, Douard V, Germain M, et al. (2004) Effects of $n-3$ polyunsaturated dietary supplementation on the reproductive capacity of male turkeys. Theriogenology $\mathbf{6 1}$, 537-549.

18. Sebokova E, Garg ML, Wierzbicki A, et al. (1990) Alteration of the lipid composition of rat testicular plasma membranes by dietary $(n-3)$ fatty acids changes the responsiveness of Leydig cells and testosterone synthesis. J Nutr 120, 610-618.

19. Marzouki ZM \& Coniglio JG (1982) Effect of essential fatty acid deficiency on lipids of rat Sertoli and germinal cells. Biol Reprod 27, 312-315.

20. Abayasekara DR \& Wathes DC (1999) Effects of altering dietary fatty acid composition on prostaglandin synthesis and fertility. Prostaglandins Leukot Essent Fatty Acids 61, $275-287$

21. Roqueta-Rivera M, Stroud CK, Haschek WM, et al. (2010) Docosahexaenoic acid supplementation fully restores fertility and spermatogenesis in male $\Delta-6$ desaturase-null mice. J Lipid Res 51, 360-367.

22. Corsetti JP, Sparks JD, Peterson RG, et al. (2000) Effect of dietary fat on the development of non-insulin dependent diabetes mellitus in obese Zucker diabetic fatty male and female rats. Atherosclerosis 148, 231-241.

23. Field CJ, Ryan EA, Thomson AB, et al. (1988) Dietary fat and the diabetic state alter insulin binding and the fatty acyl composition of the adipocyte plasma membrane. Biochem J 253, 417-424.

24. Sprando RL, Collins TFX, Black TN, et al. (1999) Light microscopic observations on the reproductive tract of the male sand rat, Psammomys obesus. Tissue Cell 31, 99-115. 
25. Industrial Reproductive Toxicology Discussion Group (IRDG) and Computer Assisted Sperm Analysis (CASA) Group (2000) Rat Sperm Morphological Assessment Guideline Document, 1st ed. http://www.irdg.co.uk/Sperm_morphology. pdf (accessed April 2011)

26. Folch J, Lees M \& Sloane Stanley GH (1957) A simple method for the isolation and purification of total lipides from animal tissues. J Biol Chem 226, 497-509.

27. Touchstone JC, Chen JC \& Beaver KM (1980) Improved separation of phospholipids in thin layer chromatography. Lipids 15, 61-62.

28. Morrison WR \& Smith LM (1964) Preparation of fatty acid methylesters and dimethylacetals from lipids with boron fluoride-methanol. J Lipid Res 5, 600-608.

29. Steel RGD, Torrie JH \& Dickey DA (1990) Principals and Procedures of Statistics. New York: McGraw-Hill.

30. Retterstøl K, Haugen TB \& Christophersen BO (2000) The pathway from arachidonic to docosapentaenoic acid (20:4n-6 to $22: 5 n-6)$ and from eicosapentaenoic to docosahexaenoic acid (20:5n-3 to $22: 6 n-3)$ studied in testicular cells from immature rats. Biochim Biophys Acta 1483, 119-131.

31. Chanmugam PS, Boudreau MD \& Hwang DH (1991) Dietary $(n-3)$ fatty acids alter fatty acid composition and prostaglandin synthesis in rat testis. J Nutr 121, 1173-1178.

32. Guerre-Millo M, Guesnet P, Guichard C, et al. (1994) Alteration in membrane lipid order and composition in metabolically hyperactive fatty rat adipocytes. Lipids 29 , 205-209.

33. West DB, Prinz WA, Francendese AA, et al. (1987) Adipocyte blood flow is decreased in obese Zucker rats. Am J Physiol 253, 228-233.

34. Lima N, Cavaliere H, Knobel M, et al. (2000) Decreased androgen levels in massively obese men may be associated with impaired function of the gonadostat. Int $J$ Obes Relat Metab Disord 24, 1433-1437.

35. Aksoya Y, Aksoy H, Altınkaynak K, et al. (2006) Sperm fatty acid composition in subfertile men. Prostaglandins Leukot Essent Fatty Acids 75, 75-79.

36. Robinson BS, Johnson DW \& Poulos A (1992) Novel molecular species of sphingomyelin containing 2-hydroxylated polyenoic very-long-chain fatty acids in mammalian testes and spermatozoa. J Biol Chem 267, $1746-1751$

37. Voss A, Reinhart M, Sankarappa S, et al. (1991) The metabolism of 7,10,13,16,19-docosapentaenoic acid to $4,7,10,13,16,19$-docosahexaenoic acid in rat liver is independent of a 4-desaturase. J Biol Chem 266, 19995-20000.

38. Young RA, Frink R \& Longcope C (1982) Serum testosterone and gonadotropins in the genetically obese male Zucker rat. Endocrinology 111, 977-981.

39. Coniglio JG, Grogan WM Jr \& Rhamy RK (1975) Lipid and fatty acid composition of human testes removed at autopsy. Biol Reprod 12, 225-259. 